IJPSR (2011), Vol. 2, Issue 3 (Research Article)

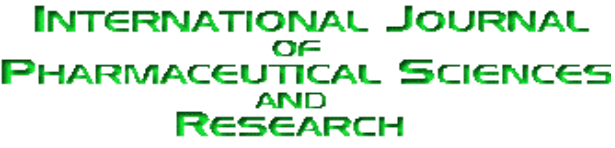

Received on 11 November, 2010; received in revised form 22 January, 2011; accepted 15 February, 2011

\title{
FORMULATION AND EVALUATION OF SOLID DISPERSION OF OLANZEPINE
}

N. S. Sheth

Sigma Institute of Pharmacy, Baroda, Gujarat, India

\section{ABSTRACT}

The poor dissolution rate of water-insoluble drugs is still a major problem conforming the pharmaceutical industry. The

Keywords:

Olanzepine,

Solid Dispersion,

Ploy ethylene glycol (PEG),

Micronization,

Solubility, Dissolution

Correspondence to Author:

Nirav S Sheth

Sigma Institute of Pharmacy, Baroda, Gujarat, India most common method for improving the solubility is by increasing the surface area of the drug through micronization. But, in practice the effect of micronization is often disappointing, especially when the drugs are encapsulated or tablet. It is generally recognized that low solubility or dissolution rate often becomes a rate-limiting step in absorption of poorly water soluble drugs. Therefore, the enhancement of the dissolution rate of poorly water-soluble drugs after oral administration is one of the most challenging aspects of modern pharmaceutics. Olanzepine (2- methyl- 4(4- methyl- 1- piperazinyl) - $10 \mathrm{H}$ - thieno [2, b] [1, 5]benzodiazepine possess antipsychotic activity and exhibits very slight solubility in water and as a consequence it exhibit low bioavailability after oral administration Therefore, the improvement of olanzepine dissolution from its oral solid dosage forms is an important issue for enhancing its bioavailability and therapeutic efficacy. The purpose of present work is to improve the solubility of Olanzepine by preparing its dispersion with polymer PEG (Poly Ethylene Glycol) using solvent evaporation technique. 
INTRODUCTION: The enhancement of oral bioavailability of poorly water soluble drugs remains one of the most challenging aspects of drug development. The rate and extent of dissolution of the active ingredient from any solid dosage form determines rate and extent of absorption of the drug. In the case of poorly water soluble drugs dissolution is the rate limiting step in the process of drug absorption. Potential bioavailability problems are arising with extremely hydrophobic drugs due to incomplete absorption from the GIT. The solid dispersion approach has been widely and successfully applied to improve the solubility, dissolution rate and consequently the bioavailability of poorly water soluble drugs. In solid dispersion method drug is dispersed in inert water soluble carrier at solid state. Solid dispersion technique is show in figure 1.

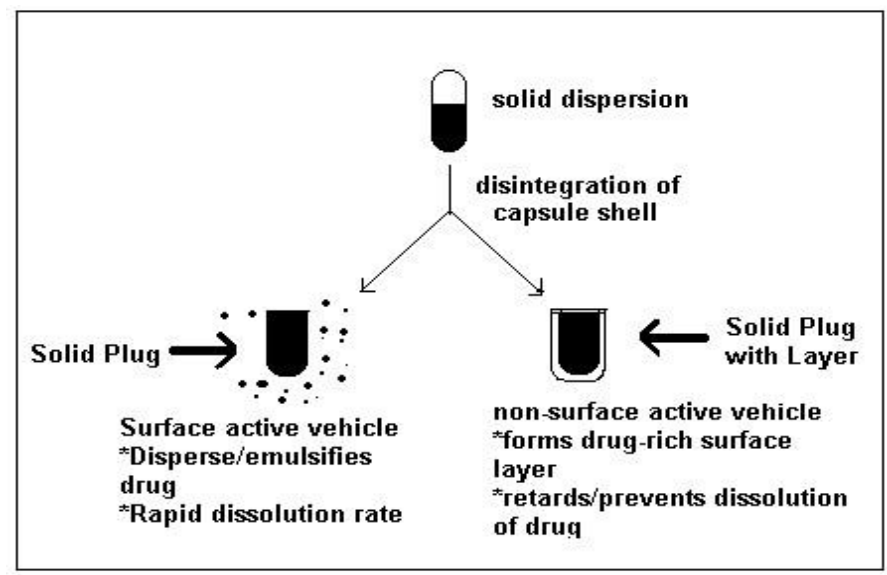

FIG. 1: SOLID DISPERSION TECHNIQUE

Definition 2: Solid dispersion is defined as "a dispersion of one or more active ingredients in an inert carrier or matrix of solid state prepared by melting (fusion), solvent or melting solvent method."

- Solid dispersion also termed as coprecipitates and melts.

- Dispersions obtained through the fusion process are often called melts.
- Dispersions obtained through the solvent method are referred as co-precipitates or co-evaporates, e.g. Cisapride- PVP solid dispersion, Piroxicam- PVP solid dispersion

Methods of preparation: There are four methods for preparation of solid dispersion.

1. Melting or Fusion method

2. Solvent method

3. Melting- Solvent method

4. Melt adsorption method.

Melting or Fusion method ${ }^{3}$ : A physical mixture of an active agent and a water soluble carrier is heated until it is melted. The melt is solidified rapidly in an ice bath under continuous stirring. The obtained mass is pulverized and then sieved. Spray congealing from a modified spray drier on to a cold metal surface has also been used to obtain the product in form of pellets. This avoids grinding step that may alter crystalline modification.

\section{Advantages:}

- Simplicity.

- Economical method.

\section{Disadvantages:}

- Method may not be suitable, if the drug or the carrier is unstable at the fusion temperature or evaporates at high temperature.

- The resulting mass may be tacky and intractable in nature.

Solvent method ${ }^{4}$ : Drug and carrier material is dissolved in a common solvent. The solvent is removed by evaporation under reduced pressure at varying temperature. The choice of solvent and its removal rate are critical to the quality of the dispersion. 
Advantages: Thermal decomposition of drugs and carriers associated with fusion method can be avoided.

\section{Disadvantages:}

- High cost of evaporation.

- Use of large quantity of solvent and difficulty in complete removal.

- The main problems associated with this method are-

- Residual solvent

- Selection of common solvent

- Difficulty to reproduce crystal form of drug

- Difficulty to attain super saturation of the solute in the solid system

Melting-Solvent Method ${ }^{2}$ : It has been found that $5-10 \%$ of liquid compounds can be incorporated in Poly Ethylene Glycols without significant loss of its solid property. Hence, it is possible to prepare solid dispersion first by dissolving the drug in a suitable liquid solvent and then incorporating the solution directly in to the melt of PEG without removing the liquid solvent.

Melt adsorption method: In melt adsorption method, materials which are having particles which have the structures of assembled petal like flakes are used as carrier for preparation of solid dispersion. Such particles contain lot of pores on surface. Because of this particles are capable of adsorbing a very large amount of material on their surface and gives solid dispersion, e.g. Porous calcium silicate (Florite RE) is useful for the preparation of solid dispersion of poorly water soluble drugs by melt adsorption method. This improves solubility and oral bioavailability of drug.

Types of solid dispersions ${ }^{5,6}$ : On the basis of major fast release mechanisms, solid dispersion in following six types.

1. Simple eutectic mixture

2. Solid solution
3. Glass solution and Glass suspension

4. Amorphous precipitation in a crystalline carrier

5. Compound or Complex formation

6. Combination of previous five methods

Mechanism of increased Dissolution rate ${ }^{7}$ : The enhancement in dissolution rate of solid dispersion as compare to pure drug can be attributed to a number of factors.

- Particle size reduction: In the case of glass, solid solutions and amorphous dispersions particle size is reduced to a minimum level. This can result in an enhanced dissolution rate due to both increase in the surface area and solubilization.

- The carrier material as it dissolves may have a solubilization effect on the drug.

- Formation of metastable dispersion that has a greater solubility would result in faster dissolution rates.

- Complex formation between drug and inert soluble carrier.

Advantages of solid dispersion ${ }^{8}$ : Provides a promising way to increase the dissolution rate of poorly water soluble drugs.

- Reduces pre-systemic metabolism, due to saturation of enzymes responsible for biotransformation of drugs.

- Provides easy transformation of the liquid form of the drug into a solid form, avoiding polymorphic changes and thereby bioavailability problems.

- Protects certain drugs against decomposition by saliva to allow buccal absorption. E.g. Cardiac glycosides by PEG.

- This technique can be valuable for drug discovery and development when the solubility of the compound is one of the key factors. 
The following figure gives schematic representation of the bioavailability enhancement of a poorly water soluble drug by solid dispersion compared with conventional tablet or capsule.

Disadvantages of solid dispersion ${ }^{8}$ : Major disadvantage is instability. Several systems have shown changes in crystalline and a decrease in dissolution rate on aging.

- Moisture and temperature have most deteriorating effect on solid dispersion than physical mixture.

- Sometimes difficult to handle because of tackiness.

Olanzepine ${ }^{9}$ :

IUPAC Name: (2-methyl-4-(4-methyl-1-piperazinyl)$10 \mathrm{H}$-thieno $[2,3-b][1,5]$ benzodiaze

\section{Structure:}
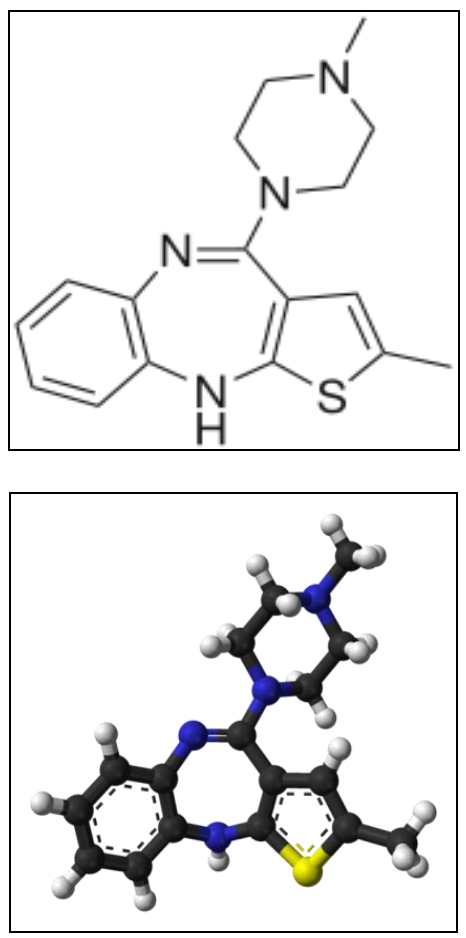

FIGURE: 2: STRUCTURE OF OLANZEPINE

The drug details are provided in table 1 which summarizes its details:
TABLE 1: DRUG DETAILS

\begin{tabular}{|c|c|c|}
\hline Drug & Parameters & \\
\hline \multirow[t]{11}{*}{ Olanzepine } & Category & Antipsychotic and neuroleptic \\
\hline & Indications & Used to treat psychotic disorders \\
\hline & Contraindication & $\begin{array}{l}\text { Hypersensitivity to this drug } \\
\text { prohibits its use. }\end{array}$ \\
\hline & $\begin{array}{l}\text { Pharmacologic } \\
\text { class }\end{array}$ & Thienobenzodiazepine \\
\hline & Therapeutic class & Antipsychotic \\
\hline & $\begin{array}{l}\text { Pharmacological } \\
\text { Action }\end{array}$ & $\begin{array}{l}\text { Thought to antagonize dopamine } \\
\text { and serotonin type } 2 \text { in CNS. Also } \\
\text { antagonizes muscarinic receptors } \\
\text { in respiratory tract, causing } \\
\text { cholinergic activation }\end{array}$ \\
\hline & Contraindications & Hypersensitivity to drug \\
\hline & $\begin{array}{l}\text { Adverse } \\
\text { reactions }\end{array}$ & $\begin{array}{l}\text { Neuroleptic malignant syndrome } \\
\text { coma, leucopenia, severe } \\
\text { hyperglycemia, headache, chest } \\
\text { pain, tachycardia } \\
\text { photosensitivity }\end{array}$ \\
\hline & Solubility & Less water solubility \\
\hline & Permeability & High permeability \\
\hline & Brands & $\begin{array}{l}\text { Zyprexa, Zyprexa intramuscular } \\
\text { Zyprexa Zydis. }\end{array}$ \\
\hline Route & Onset & Duration \\
\hline P.O. & Unknown & Unknown \\
\hline I.M. & Rapid & $15-45 \min$ \\
\hline
\end{tabular}

Olanzepine is used in preparation of solid dispersion because it is having less water solubility.

MATERIALS AND METHODS: Olanzepine was obtained as the gift sample from Alembic Pharmaceutical limited, (Baroda, and Gujarat, India.) PEG (Poly Ethylene Glycol), Methanol, Phosphate Buffer pH 6.8, Distilled Water. All other chemicals were used of analytical grade.

Instruments used: Electronic Balance, Water bath, UV/visible Spectrophotometer, Dissolution Apparatus

\section{Methods of estimation of olanzepine:}

Preparation of Phosphate buffer pH 6.8: Sodium hydroxide in quantity of $0.9 \mathrm{gm}$ and $6.8 \mathrm{gm}$ of potassium dihydrogen phosphate were dissolved in 
one liter of distilled water to produce phosphate buffer $\mathrm{pH} 6.8$.

Preparation of Stock solution: 20mg of Olanzepine was dissolved in sufficient quantity of methanol and dilute with phosphate buffer $\mathrm{pH} 6.8$ to mark in $100 \mathrm{ml}$ volumetric flask to obtain a stock solution.

Determination of UV absorption maxima: $2 \mu \mathrm{g} / \mathrm{ml}$ solution of olanzepine was prepared by addition of $2 \mathrm{ml}$ of stock solution in $100 \mathrm{ml}$ volumetric flask in phosphate buffer $\mathrm{pH} 6.8$ and was scanned for for absorbance between 200-400nm using Shimadzu UV/Visible spectrophotometer. Olanzepine exhibit UV absorption of maxima $254 \mathrm{~nm}$.

Preparation of Calibration curve: Aliquots of 2, 4, 6,8 and $10 \mathrm{ml}$ were transferred to $100 \mathrm{ml}$ volumetric flasks and were serially diluted with phosphate buffer $\mathrm{pH} 6.8$, to the mark to obtain olanzepine conc. $2,4,6,8,10 \mu \mathrm{g} / \mathrm{ml}$ respectively. Absorbance of each solution was measured at 254 $\mathrm{nm}$ using Shimadzu UV/visible spectrophotometer against phosphate buffer $\mathrm{pH} 6.8$ as a blank. The absorption of olanzepine is shown in Table 2 \& slope as well as $R^{2}$ is shown in figure 3 .

\section{TABLE 2: PREPARATION OF CALIBRATION CURVE}

\begin{tabular}{cc}
\hline Concentration $(\mu \mathrm{g} / \mathrm{ml})$ & Abs \\
\hline 2 & 0.345 \\
4 & 0.451 \\
6 & 0.568 \\
8 & 0.679 \\
10 & 0.834 \\
\hline
\end{tabular}

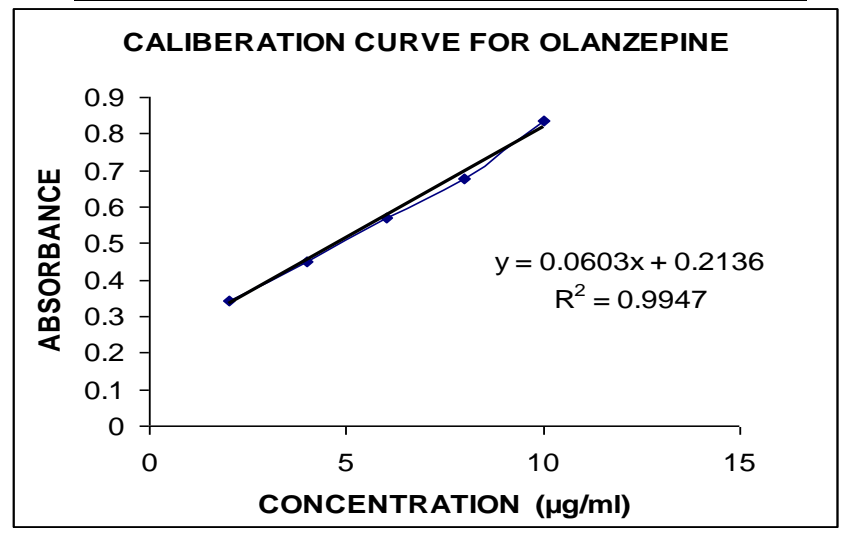

FIG. 3: CALIBRATION CURVE OF OLANZEPINE
Preparation of physical mixture: Olanzepine and PEG were weighed according to requirements for the preparation of capsules of different ratio [Olanzepine: PEG, P-1 (100mg: 200mg), P-2 (100mg: 300mg), P-3 (100mg: 400mg), P-4 (100mg: $500 \mathrm{mg})]$. And then capsules were filled with physical mixture and dissolution study was performed using Dissolution Apparatus for three hours and then $5 \mathrm{ml}$ sample of each ratio was withdrawn at the interval of $30 \mathrm{~min}$ and its absorbance was measured and then finally percentage cumulative release was calculated. It shows in figure 4.

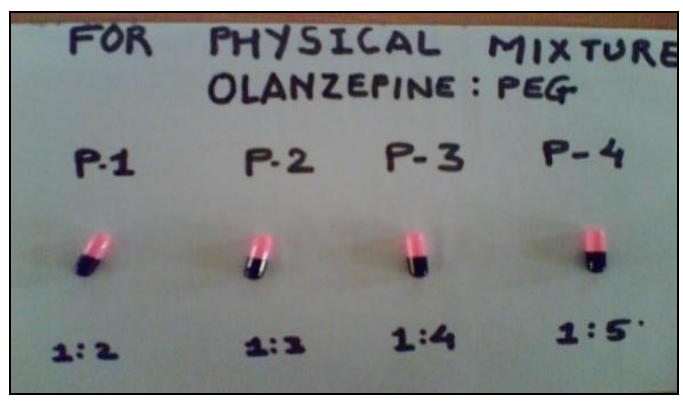

FIG. 4: PREPARATION OF CAPSULES FOR PHYSICAL MIXTURE

Preparation of solid dispersion: Olanzepine and PEG were weighed according to requirements for the preparation of capsules of different ratio [Olanzepine: PEG, S-1 (100mg: 200mg), S-2 (100mg: $300 \mathrm{mg}$ ), S-3 (100mg: 400mg), S-4 (100mg: 500mg)]. Then sufficient amount of Methanol was added to dissolve the olanzepine and PEG. Lastly the solvent was evaporated using solvent evaporation method on water bath. Crystals were collected and filled in capsules and dissolution study was performed using Dissolution apparatus for three hours and then $5 \mathrm{ml}$ sample of each ratio was withdrawn at the interval of $30 \mathrm{~min}$ and its absorbance was measured and then finally percentage cumulative release was calculated. It shows in figure $\mathbf{5}$. The formulation of both physical mixture and solid dispersion is provided in table 3. 

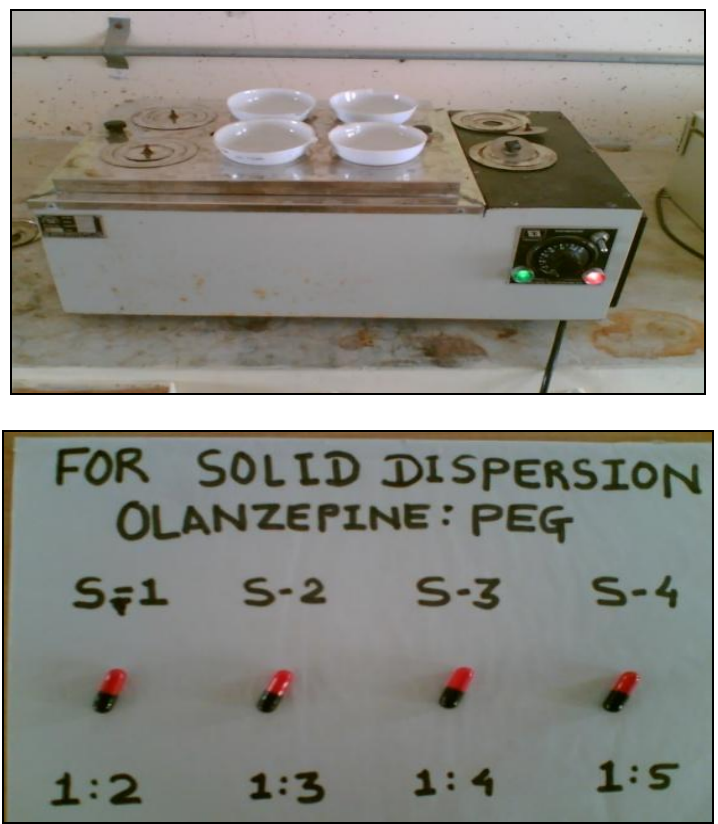

FIG. 4: PREPARATION OF CAPSULES FOR PHYSICAL MIXTURE

TABLE 3: FORMULATION TABLE FOR PHYSICAL MIXTURE AND SOLID DISPERSION

\begin{tabular}{ccccccccccc}
\hline Materials & \multicolumn{3}{c}{ Physical mixture } & \multicolumn{5}{c|}{ Solid dispersion } \\
\hline & P-1 & P-2 & P-3 & P-4 & S-1 & S-2 & S-3 & S-4 \\
& $1: 2$ & $1: 3$ & $1: 4$ & $1: 5$ & $1: 2$ & $1: 3$ & $1: 4$ & $1: 5$ \\
$\begin{array}{c}\text { Olanzepine } \\
\text { (mg) }\end{array}$ & 100 & 100 & 100 & 100 & 100 & 100 & 100 & 100 \\
$\begin{array}{c}\text { PEG (mg) } \\
\text { Methanol }\end{array}$ & 200 & 300 & 400 & 500 & 200 & 300 & 400 & 500 \\
\hline
\end{tabular}

In vitro dissolution study: In vitro dissolution study of Olanzepine capsules were carried out in $900 \mathrm{ml}$ $6.8 \mathrm{~N}$ buffer using USP basket apparatus. The temperature was maintained $37 \pm 0.5^{\circ} \mathrm{C}$ and agitation rate of basket was set to 100rpm. Sample $(5 \mathrm{ml})$ was withdrawn at predetermined time intervals, and dilute, if necessary with $6.8 \mathrm{pH}$ buffer. The same volume of fresh dissolution medium was replenished immediately after the sample was withdrawn. The absorbance was measured at $254 \mathrm{~nm}$ using UV/visible spectrophotometer to determine cumulative \% drug released. The amount of drug released was calculated using equation generated from standard calibration curve data. Results are show in table 4 \& table 5 .

\section{RESULT:}

For Physical Mixture:

TABLE 4: DISSOLUTION PROFILE OF PHYSICAL MIXTURE:

\begin{tabular}{ccccc}
\hline \multirow{2}{*}{ Time (min) } & \multicolumn{4}{c}{ \% Cumulative Release } \\
\cline { 2 - 5 } & $\mathbf{P - 1}$ & $\mathbf{P - 2}$ & $\mathbf{P}-\mathbf{3}$ & $\mathbf{P}-\mathbf{4}$ \\
\hline 10 & 0.19 & 1.50 & 3.14 & 8.05 \\
30 & 2.95 & 5.94 & 9.55 & 25.46 \\
60 & 6.13 & 8.04 & 15.16 & 40.11 \\
90 & 7.89 & 10.64 & 21.16 & 43.10 \\
120 & 11.8 & 13.40 & 29.14 & 58.01 \\
150 & 19.79 & 29.29 & 44.20 & 66.11 \\
180 & 27.8 & 45.92 & 65.32 & 69.08 \\
\hline
\end{tabular}

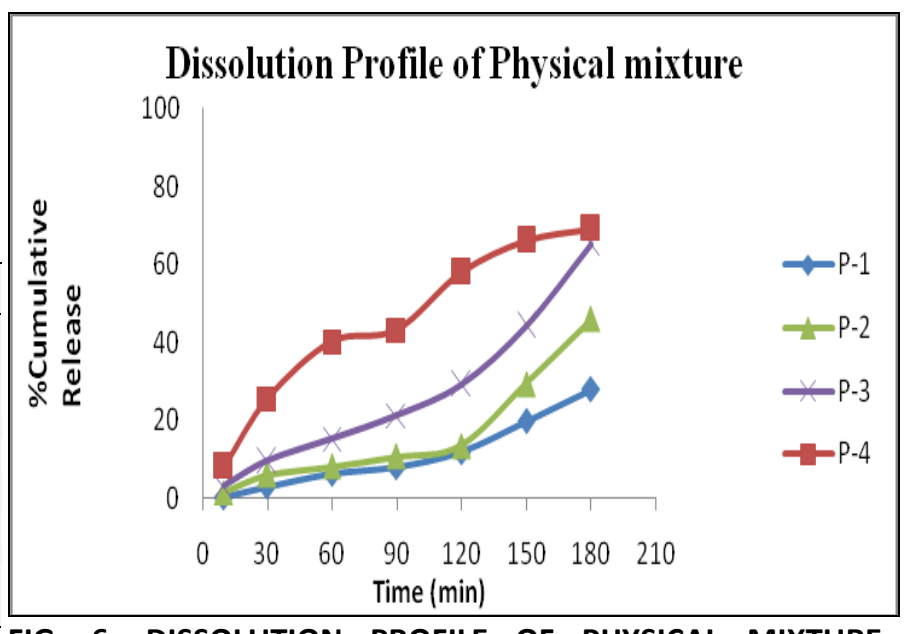

FIG. 6: DISSOLUTION PROFILE OF PHYSICAL MIXTURE DISPERSION

For Solid Dispersion:

TABLE 5: DISSOLUTION PROFILE OF SOLID DISPERSION

\begin{tabular}{ccccc}
\hline \multirow{2}{*}{ Time $(\boldsymbol{m i n})$} & \multicolumn{4}{c}{ \%Cumulative Release } \\
\cline { 2 - 5 } & S-1 & S-2 & S-3 & S-4 \\
\hline 10 & 4.46 & 4.49 & 12.76 & 16.32 \\
30 & 8.58 & 15.08 & 20.91 & 32.23 \\
60 & 13.79 & 27.47 & 40.85 & 53.62 \\
90 & 26.83 & 35.64 & 53.58 & 59.59 \\
120 & 39.19 & 43.86 & 61.2 & 77.22 \\
150 & 43.37 & 61.11 & 68.67 & 84.25 \\
180 & 56.34 & 68.31 & 79.89 & 90.32 \\
\hline
\end{tabular}




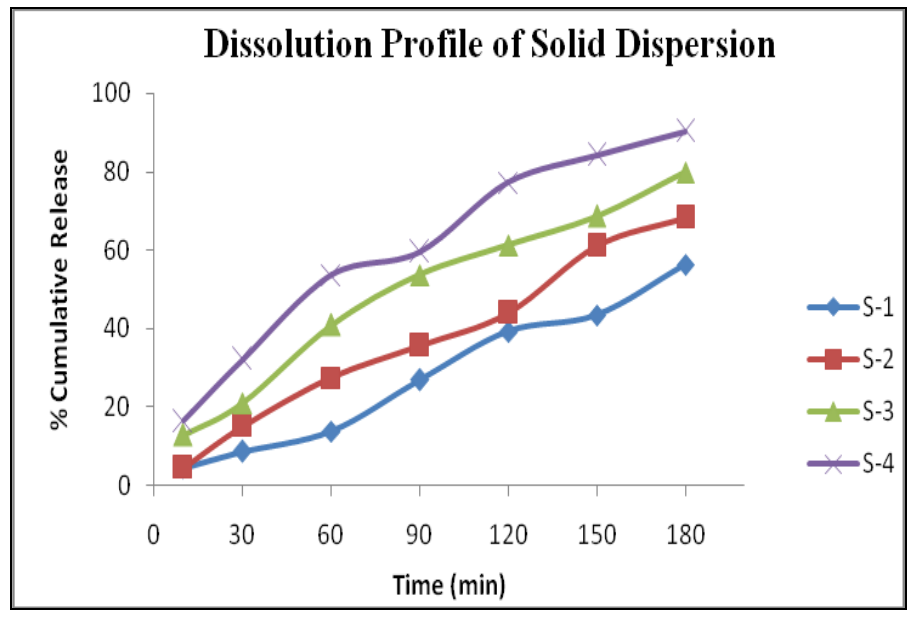

FIG. 7: DISSOLUTION PROFILE OF SOLID DISPERSION

CONCLUSION Olanzepine is practically insoluble in water. However, its very low aqueous solubility and poor dissolution can cause formulation problems and limit its therapeutic application by delaying the rate of absorption and the onset of action. By comparing the formulation and evaluation of solid dispersion of olanzepine with physical mixture of olanzepine, the obtained data showed that there was linearly increased in dissolution profile of solid dispersion and physical mixture compared to plain drug. So, it can be concluded that solid dispersion of olanzepine with ploy ethylene glycolin (PEG) increased the solubility of drug.

\section{REFERENCES:}

1. Sekiguchi K, Obi N, "Studies on absorption of eutectic mixtures. I. A comparison of the behavior of eutectic mixtures of sulphathiazole and that of ordinary sulphathiazole in man", Chem. Pharm. Bull 1961; 9:866872.

2. Chiou WL, Riegelman S. "Pharmaceutical applications of solid dispersion system”. J Pharma Sci 1971; 60:1281-1302.

3. Goldberg A, Gibaldi M, Kanig J L, "Increasing dissolution rates and gastrointestinal absorption of drugs via solid solutions and eutectic mixtures III - experimental evaluation of griseofulvin- succinic acid solid solution", J. Pharm. Sci. 1966; 55:487-492.

4. Serajuddin A., "solid dispersion technique", J. Pharm. Sci. 1999; 88(10): 891-900.

5. Simonelli AP, Mehta SC and Higuchi WI, Dissolution rates of high energy polyvinylpyrrolidone (PVP)-sulfathiazole co precipitates. J. Pharm. Sci., 1969; 58(5):538-549

6. Mullins JD and Macek TJ. Some pharmaceutical properties of novobiocin. J. Am. Pharm. Assoc. Sci. Ed., 1960; 49:245248.

7. Abu TMS. "Solid dispersion of poorly water soluble drugs: Early promises, subsequent problems and recent breakthroughs." J. Pharm. Sci 1999; 88:1058-1066.

8. N rama rao, international journal of pharmaceutical excipients 2001; 2 (1): 186-189

9. http://encyclopedia.thefreedictionary.com/Olanzepine (21 Oct, 2010) 